\title{
Assessing the Efficacy of Treatments for the Deficit Syndrome of Schizophrenia
}

\author{
Brian Kirkpatrick, M.D., Alex Kopelowicz, M.D., Robert W. Buchanan, M.D., \\ and William T. Carpenter, Jr., M.D.
}

The primary, enduring negative symptoms found in some patients with schizophrenia have become the focus of clinical treatment trials, but there has been no consensus on the best methods for approaching this area. In future trials, a number of issues need to be considered, including analytic strategies, the limitations in instruments used to measure negative symptoms, and study design. An appropriate design for establishing the efficacy of treatments for the deficit syndrome is proposed.

[Neuropsychopharmacology 22:303-310, 2000] (C) 2000 American College of Neuropsychopharmacology. Published by Elsevier Science Inc.
KEY WORDS: Schizophrenia; Treatment; Negative symptoms

From the earliest descriptions of dementia praecox, it has been recognized that many patients with schizophrenia have an amotivational syndrome that is associated with severe impairments. In his textbook, Kraepelin (1971) stated that one of "two fundamental processes underlying dementia praecox" resulted in a "weakening of the mainsprings of volition," and "the destruction of the personality."

In the 1970's, results from the International Pilot Study of Schizophrenia demonstrated that this aspect of the psychopathology of schizophrenia had a remarkable degree of cross-sectional and longitudinal independence from other symptom complexes (Strauss et al. 1974). The implications of these findings, and the publication of factor-analytic studies of the symptoms of schizophrenia (Andreasen et al. 1995; Buchanan and Carpenter 1994), increased the attention paid to these

From the Maryland Psychiatric Research Center, Department of Psychiatry (BK, RWB, WTC), University of Maryland, Baltimore, MD; and San Fernando Mental Health Center, Department of Psychiatry (AK), University of California Los Angeles, Mission Hills, CA.

Address correspondence to: Brian Kirkpatrick, M.D., MPRC, PO Box 21247, Baltimore, MD 21228.

Received November 5, 1998; revised June 16, 1999; accepted September 13, 1999. clinical features. With the development of rating scales for negative symptoms, and Crow's proposal (Crow 1985) that Type II schizophrenia differed from other forms of schizophrenia relative to pathophysiology, this area has become the subject of extensive research.

This aspect of the psychopathology of schizophrenia has in recent years become been an important focus in treatment trials. Pharmaceutical companies now seek FDA approval to promote their drugs as effective treatments for negative symptoms, and negative symptom ratings are routinely outcome variables for data analysis in studies of both psychopharmacology and pathophysiology. In the reports of some clinical trials, it has been stated that a drug is significantly more effective than placebo in the treatment of the primary negative symptoms of schizophrenia. However, a variety of approaches have been used to assess efficacy. This is a complex issue, and a careful consideration of design and analysis issues would be timely.

\section{THE DEFINITION OF NEGATIVE SYMPTOMS}

In his textbook, Kraepelin (1971) gave a vivid description of a group of patients with severe negative symptoms. He proposed they had suffered "a weakening of those emotional activities which permanently form the 
mainsprings of volition ... The essence of personality is thereby destroyed, the best and most precious part of its being ... torn from her... (resulting in) complete and final destruction of the personality itself." This description implies certain things about the group of patients he described. First, the impairment is primary or idiopathic, that is, part of the disease itself. Second, the impairment is enduring (the destruction of the personality).

Criteria for the deficit syndrome (Kirkpatrick et al. 1989) (Table 1), and a semistructured instrument for diagnosing deficit vs. nondeficit groups, the Schedule for the Deficit Syndrome (SDS) (Kirkpatrick et al. 1989), were developed for the purpose of studying primary, enduring negative symptoms. The deficit/nondeficit categorization can be made with good interrater reliability (Kirkpatrick et al. 1989; Fenton and McGlashan 1992; Amador et al. 1999), although raters who have not been trained do not have good agreement (Flaum and Andreasen 1995).

Research has shown the deficit group differs from other patients with chronic schizophrenia on a variety of measures. These include course of illness, neurocognitive measures, and functional and structural imaging variables (Breier et al. 1994; Kopelowicz et al. 1997; Dollfus et al. 1996; Waltrip et al. 1997; Tamminga et al. 1992; Carpenter et al. 1996; Buchanan et al. 1990, 1993, 1994, 1997; Fenton et al. 1994; Fenton and McGlashan 1992, 1994; Ross et al. 1996; Bustillo et al. 1997; Kirkpatrick and Buchanan 1990, 1994, 1996a,b,c). The differences between deficit and nondeficit groups cannot be attributed to a greater severity, in the deficit patients, of positive psychotic symptoms, drug abuse, anxiety or depression, as relative to all of these measures, they either

Table 1. Criteria for the Deficit Syndrome of Schizophrenia

1. At least two of the following six negative symptoms must be present

a. restricted affect

b. diminished emotional range

c. poverty of speech

d. curbing of interests

e. diminished sense of purpose

f. diminished social drive

2. some combination of two or more of the negative symptoms listed above have been present for the preceding 12 months and always were present during periods or clinical stability (including chronic psychotic states). These symptoms may or may not be detectable during transient episodes of acute psychotic disorganization or decompensation

3. The negative symptoms above are primary, i.e., not secondary to factors other than the disease process. Such factors include: a. anxiety

b. drug effect

c. suspiciousness (and other psychotic symptoms)

d. mental retardation

e. depression

4. The patient meets DSM-III(R) or -IV criteria for schizophrenia do not differ from nondeficit patients or have a lesser severity of the problem (Kirkpatrick et al. 1989, 1993, 1994). In some brain regions, deficit patients have a more normal gross anatomy, as measured by volume, than do nondeficit patients (Buchanan et al. 1993).

An important issue in treatment trials is the extent to which negative symptom rating scales, which are used to measure change in this area of psychopathology, capture the idiopathic amotivational syndrome found in some patients with schizophrenia. The Scale for the Assessment of Negative Symptoms (SANS) (Andreasen 1982) is widely used in studies of pathophysiology and treatment, was the first scale designed specifically for negative symptoms, and has been the most influential conceptually. The issues it illustrates are also relevant for other negative symptom rating scales such as the Positive and Negative Syndromes Scale (PANSS), or the anergia factor of the Brief Psychiatric Rating Scale (BPRS). The SANS has five subscales: alogia (poverty of speech and poverty of content of speech); affective flattening or blunting; avolition-apathy; anhedonia-asociality; and attention. It reflects the "agnosticism" as to causation that has been influential in the development of psychiatric diagnostic and ratings systems in recent years. One reason why this approach is attractive is that it may facilitate the development of strong interrater reliability. However, relative to quantifying Kraepelin's "weakening of the mainsprings of volition," the SANS, as a consequence, does not distinguish primary from secondary negative symptoms. It also does not distinguish transient (state) versus enduring (trait) features, and includes impairments beyond the "destruction of the personality."

\section{State versus Trait Symptoms}

The severity of negative symptom ratings can be highly variable for an individual patient, changing as the patient's positive psychotic symptoms (hallucinations, delusions, and formal thought disorder) fluctuate. This variation makes any putative biological subtype based on cross-sectional assessment less likely to have a relationship to underlying pathophysiology.

\section{Primary versus Secondary Negative Symptoms}

The concept of negative symptoms as quantified in current rating scales differs from an operationalization of Kraepelin's concept of an unemotional, amotivational patient, as the symptoms quantified by these scales can be the result, not only of a loss of a psychological function, but of other problems as well. For instance, consider the item "impersistence at work or school," from the SANS. A patient may not persist at such tasks because of severely disorganized thinking; because his or her hallucinations are terribly distracting; because he or 
she suffers from Kraepelin's amotivational syndrome; because of the problems with memory and attention suffered by patients with schizophrenia; because of depression; or for a number of other reasons. The patient who suffers from any of the problems other than the idiopathic syndrome found in schizophrenia would have "secondary" negative symptoms, in contrast to the "primary" negative symptoms of the deficit syndrome (Carpenter et al. 1985, 1988; Kirkpatrick et al. 1989). The issue of differential diagnosis is relevant for all of the other SANS items as well. Treatments that improve psychotic symptoms, depression, the cognitive problems associated with schizophrenia, or anxiety may also improve negative symptoms as they are presently defined by rating scales.

\section{Specific Items}

The many factor analytic studies of the symptoms of schizophrenia provide a basis for selecting those items that belong within the realm of negative symptoms. Despite the differences among these studies, including the use of different rating instruments, there has been a striking degree of agreement across studies. Several items rather consistently load onto a negative symptom factor, including those related to blunted affect, poverty of speech, decreased spontaneous movement (when this is included as an item), and avolition or apathy (Buchanan and Carpenter 1994). Items more closely related to the disorganization syndrome of schizophrenia, such as poverty of content of speech (Buchanan and Carpenter 1994; Andreasen et al. 1995) are sometimes considered negative symptoms (Andreasen 1982). Attentional impairments frequently load onto a negative symptom factor, but items measuring poor attention on clinical interview have also frequently been part of disorganization factors (Buchanan and Carpenter 1994).

In the SANS, attentional impairment constitutes one of the five subscales. Consequently, when there is a change in items such as poverty of content of speech or attention in a group in a clinical trial, it is not clear if this improvement is due to effective treatment of the amotivational syndrome of schizophrenia.

Besides the negative symptoms items that have been found to covary in these studies, the SANS and similar scales also have a number of items that measure quality of life or level of function. In the SANS, excluding the global rating item in each subscale, there are a number of items that are measurements of these other domains: grooming and hygiene; impersistence at work of school; recreational interests and activities; sexual interest and activity; ability to feel intimacy and closeness; and relationships with friends and peers. To say that negative symptom ratings predict quality of life or level of function is redundant: negative symptom rating scales often measure level of function.
In short, what has historically concerned investigators when we talk about the psychopathology that is now called negative symptoms, is the unmotivated, unemotional, asocial patient. But what negative symptom scales measure is something much broader, and overlaps extensively with what in other areas of medicine would be called activities of daily living, quality of life, or functional outcome. Negative symptoms, defined so broadly, change as other problems, which are sources of secondary negative symptoms - such as extrapyramidal symptoms, positive psychotic symptoms, and dysphoria-also change. This theoretical distinction between the primary, enduring symptoms of the deficit syndrome and negative symptoms, as more broadly defined by such instruments as the Scale for the Assessment of Negative Symptoms, has proven to be meaningful, as the correlates of the deficit syndrome and those of negative symptoms more broadly defined have been shown to differ (Kirkpatrick et al. 1993, 1996a, 1998, in press; Tamminga et al. 1992).

\section{TREATMENT TRIALS}

Table 2 lists the reports of controlled, double-blind treatment trials that claim efficacy for either the deficit syndrome or primary negative symptoms. This claim has been based on one or more of the following: 1) efficacy for negative symptoms; 2) a path analysis; or 3) efficacy in a putative deficit syndrome group. However, the strength of the evidence for efficacy of this kind is in some instances undermined by the methods used to support the conclusion.

\section{Efficacy for Negative Symptoms}

As explained above, negative symptoms as they are quantified on the SANS and PANSS do not accurately reflect the concept that has been the focus of research for more than a century. Furthermore, a group with severe negative symptoms is not the same as a deficit syndrome group and has different correlates (Kirkpatrick et al. 1989, 1993, 1996a, 1998, 1999). To say that patients with prominent or severe negative symptoms comprise a meaningful deficit syndrome group is similar to diagnosing panic disorder in every patient with anxiety, or diagnosing schizophrenia in every patient with delusions. Consequently, reports of efficacy for negative symptoms, however desirable such efficacy may be, do not inform us about efficacy for the deficit syndrome. The "typical" neuroleptics such as chlorpromazine and haloperidol have been known for some time to treat negative symptoms as defined by negative symptom rating scales (Buchanan et al. 1996; Goldberg 1985; Meltzer et al. 1986; Opler et al. 1994). However, these drugs are not effective treatments for deficit features. 
Table 2. Reports Claiming Efficacy for Primary Negative Symptoms (Double-Blind Studies)

\begin{tabular}{lll}
\hline Drug (and reference) & \multicolumn{1}{c}{ Basis of Claim } & Comment \\
\hline $\begin{array}{l}\text { Olanzapine } \\
\text { (Tollefson and Sanger 1997) }\end{array}$ & Path analysis & Basis of the claim is unexplained variance \\
$\begin{array}{l}\text { Risperidone } \\
\text { (Moller et al. 1996) }\end{array}$ & Path analysis & Basis of the claim is unexplained variance \\
$\begin{array}{c}\text { Amisulpride } \\
\text { (Paillere-Martinot et al. 1995) }\end{array}$ & Improvement in negative symptoms & $\begin{array}{c}\text { Positive symptoms improved 25\%, depressive } \\
\text { retardation 37\%, and depression } 42 \%\end{array}$ \\
$\begin{array}{c}\text { Amisulpride } \\
\text { (Boyer et al. 1995) }\end{array}$ & Improvement in negative symptoms & $\begin{array}{c}\text { Positive symptoms improved 38\% on the high } \\
\text { dose and } 40 \% \text { on the low dose }\end{array}$ \\
$\begin{array}{c}\text { Amisulpride } \\
\text { (Loo et al. 1997) }\end{array}$ & Improvement in negative symptoms & $\begin{array}{c}\text { Extrapyramidal symptoms improved 37\% and } \\
\text { attentional impairment } 43 \%\end{array}$ \\
$\begin{array}{l}\text { D-cycloserine } \\
\text { (Goff et al. 1999) }\end{array}$ & Improvement in negative symptoms & $\begin{array}{c}\text { Deficit/nondeficit categorization made prior to } \\
\text { randomization }\end{array}$ \\
\hline
\end{tabular}

A claim for efficacy is further weakened if common and important causes of secondary negative symptoms improve concomitantly with an improvement of negative symptoms, as the most likely interpretation is that improvement in the latter is due to improvement in the former. For instance, in a trial of amisulpride there was a $40 \%$ improvement in positive symptoms, as well as an improvement in negative symptom ratings (Boyer et al. 1995). In another trial of the same drug, although the improvement in the Scale for the Assessment of Positive Symptoms was just 7\%, there was a 37\% improvement in extrapyramidal symptoms (Loo et al. 1997). No data were presented on depressive symptoms, which constitute another important cause of secondary negative symptoms. In contrast, oral glycine has been shown to improve negative symptoms, in the absence of an improvement in psychotic symptoms (Heresco-Levy et al. 1999). The results with glycine provide somewhat stronger evidence that this drug has an effect on primary negative symptoms, although it is not definitive.

\section{Path Analysis}

Some recent reports have suggested that the negative symptoms of schizophrenia are "directly" responsive to treatment with olanzapine or risperidone (Tollefson and Sanger 1997; Moller et al. 1996), based on the results of path analysis. Path analysis is a statistical technique based on a model of expected or predicted relationships which is tested by the fit of actual data. In principle, if the model contains the variables which account for all of the variance in the dependent or outcome variable, then no residual "unexplained" variance would remain (Breckler and Steven 1990). In the case of path analyses of negative symptom change in clinical trials, the unexplained variance in the model would represent a therapeutic effect on primary negative symptoms only to the extent that all other possible sources of variance are contained in the model. No path analysis of negative symptom treatment efficacy approaches this standard.
As applied to studies of respiridone and olanzapine, up to three variables have been included in the models, and estimate the maximum possible effect on primary negative symptom ratings, without estimating the minimal possible effect. Many secondary sources, such as sedation, environmental stimulation, anxiety, demoralization, and dysphoric or psychomotor effects other than extrapyramidal symptoms (Carpenter et al. 1988; Kirkpatrick et al. 1993) are not included. Nor is any attempt made to include psychometric sources of variance, such as less than perfect interrater reliability, less than perfect validity of assessment instruments, or any time lag between the assessment of the secondary source and the therapeutic effect on negative symptom ratings. To refer to unexplained variance as a direct effect is to use a statistical term referring to variance not accounted for by variables in the model. In practical application, not all sources are included and the unexplained variance provides an estimate of the model's robustness. Others have raised concerns about the use of path analysis in this context (Collaborative Working Group on Clinical Trial Evaluations 1998).

\section{Efficacy in a Putative Deficit Syndrome Group}

Patients may exhibit negative symptoms because of a suspicious withdrawal, depression, distraction by auditory hallucinations, or any of a number of factors other than the idiopathic loss of motivation and liveliness (Kirkpatrick et al. 1989, 1994). Therefore, efficacy in patients with "prominent" negative symptoms (Tollefson and Sanger 1997) also provides very weak evidence about efficacy for the deficit syndrome.

A method for approximating a deficit syndrome group that does not require administration of the SDS, the Proxy for the Deficit Syndrome (PDS), has been developed and validated (Kirkpatrick et al. 1993, 1996a,b,c, in press). The basis of the PDS is assignment to each patient of a score that quantifies the severity of deficit-like 
features (the combination of core negative symptoms and an absence of dysphoria).

In multiple studies, this method has yielded deficit and nondeficit groups similar to those defined by the SDS (Kirkpatrick et al. 1993, 1996a,b,c). However, the delineation of valid groups depends on appropriate application of this method. First, although the sensitivity and specificity of this method relative to the SDS are good, there are some misclassifications. In large datasets, it is therefore advantageous to omit a group with intermediate PDS scores because of their ambiguous classification (Kirkpatrick et al. 1993). Second, even in clinical groups with severe and chronic illness, the prevalence of the deficit syndrome is probably no more than $20-30 \%$ (Kirkpatrick et al. 1993). A proxy-defined group with a much higher percentage of patients is likely to include a substantial proportion of nondeficit patients, who are more liable to secondary negative symptoms and, therefore, more likely to improve as positive psychotic symptoms and depressive mood improve. Third, after the deficit/nondeficit categorization is made, it is important to test its validity by comparing the clinical features of the putative deficit and nondeficit groups to those of groups diagnosed with the Schedule for the Deficit Syndrome (Kirkpatrick et al. 1993, 1996a,b,c).

In one recent study, the PDS was used to define a putative deficit group, and olanzapine was presented as an effective treatment for deficit features (Tollefson and Sanger 1997). However, the principles for use of the PDS outlined above were ignored: the deficit group was about half of the sample, and there was no validity testing of the categorization prior to hypothesis testing. This study does not, therefore, provide a reasonable basis for concluding that olanzapine is an effective treatment for deficit features. In a trial of clozapine, another kind of proxy method was used (Rosenheck et al. 1999). However, the two groups were not validated by comparing their clinical features, and again, the deficit group consisted of approximately half the sample. Therefore, it seems unlikely that this putative deficit group was similar to one defined by the SDS.

Large multicenter trials funded by pharmaceutical companies provide important information for our field. Because the training needed to make the deficit/nondeficit categorization is extensive, it may not be practical for companies to make this categorization using the SDS. Use of the PDS may therefore become more widespread. However, proper application is crucial if the reader is to have confidence in any results based on the PDS.

\section{APPROPRIATE DESIGNS FOR TREATMENT TRIALS}

Negative symptoms represent important problems in the lives of people with schizophrenia, so there is great practical importance in developing effective treatments for these impairments, whether they are primary or secondary. However, choosing the most appropriate design depends on whether the target of treatment consists of negative symptoms as defined by negative symptom rating scales, the negative symptoms of the deficit syndrome, or both. A consideration common to all of these designs is the duration of the treatment trial. Many of the items in negative symptom rating scales relate to areas of function in which it is difficult to demonstrate improvement in a short period, no matter how much the patient's capacities may have changed. Examples from the SANS would include impersistence at work or school—as it may take time to find a job or resume schooling - and the items for sexual interest and activity, ability to feel intimacy and closeness, and relationships with friends and peers, as significant relationships usually do not develop quickly. In order to see an effect in these areas, treatment trials of negative symptoms may need to last well beyond the conventional six or eight weeks.

\section{The Treatment of Persistent Negative Symptoms}

To establish efficacy for negative symptoms as defined by current rating scales, it may be desirable to enter only those patients with enduring negative symptoms, as it is these patients who are most impaired by such symptoms, and any interference with the interpretation of study results, due to spontaneous improvement, should thereby be minimized. It would also strengthen the design to ensure that the treatment groups do not differ at baseline relative to the severity of negative symptom ratings. However, given the current scales for negative symptoms, even if a treatment should prove to be efficacious, it would not be clear what the basis of the efficacy might be. Did the treatment improve negative symptom ratings because of decreased hallucinations, delusions, or formal thought disorder? Are the patients less depressed, and therefore exhibiting fewer negative symptoms? Was there an improvement in primary negative symptoms?

\section{The Treatment of the Deficit Syndrome}

A study design that is adequate for a treatment trial of negative symptoms does not suffice for the design of trials of the deficit syndrome. The most appropriate method for testing the hypothesis that a drug or a psychosocial intervention is efficacious in the treatment of the deficit syndrome is to enter into the trial patients who have previously been categorized into deficit and nondeficit groups. If a drug has been established as efficacious for the treatment of negative symptoms, the response of the nondeficit group would provide a context for the interpretation of the intervention's efficacy, or lack of efficacy, in the deficit group. 
Even with such a design, there is the potential for an ambiguous interpretation. Although by definition only deficit patients have enduring primary negative symptoms, they are also liable to the occurrence of secondary negative symptoms. By definition, they should not be very liable to depression-induced negative symptoms, but medication side effects, confusion or distraction during the exacerbation of psychotic symptoms, and some other causes of secondary negative symptoms should affect them as well as nondeficit patients. Any treatment trial demonstrating efficacy for primary negative symptoms would benefit from an examination of changes in psychotic symptoms, as well as group differences in medication side effects. In the case of an improvement of both negative and psychotic symptoms, the results of a trial could remain ambiguous.

This approach has been used in recent clinical trials. In one, d-cycloserine was found to be superior to placebo as an adjunct to neuroleptics in the treatment of negative symptoms in deficit patients (Goff et al. 1999). In the other, social skills training improved negative symptoms in nondeficit, but not deficit, patients (Kopelowicz et al. 1997). In the social skills trial, the deficit and nondeficit groups were matched at baseline on the severity of their negative symptom ratings; doing so further strengthens this design. A similar design has also been used in a trial of clozapine (Buchanan et al., 1998).

These last two trials raise an important issue for future trials. While the deficit/nondeficit categorization can be made with good interrater reliability, the problem of intergroup reliability remains. Some contradictions in the correlates of the deficit syndrome may be attributable to a lack of intergroup reliability (Gur et al. 1994; Nibuya et al. 1995; Ribeyre et al. 1994; Tamminga et al. 1992; Thibaut et al. 1998). Whether researchers at different sites are defining similar patient groups cannot, at this point in the development of the field, be taken for granted. However, a detailed presentation of the clinical features of the deficit and nondeficit groups would permit comparisons across trials. Specifically, it would be reassuring to know that compared to the nondeficit group, the deficit patients in clinical trials: 1) have positive symptoms (hallucinations, delusions, and formal thought disorder) that are not more severe than those of the nondeficit group; 2) have less severe dysphoric symptoms (e.g., depressive mood, anxiety, guilt, and hostility); 3) have a lesser severity of suspiciousness (Kirkpatrick et al. 1996a,b,c, 1993, 1994, 1989, 1998); and 4 ) have a similar duration of illness.

\section{CONCLUSIONS}

Making the deficit/nondeficit categorization is more complex than administering the PANSS or SANS. It re- quires longitudinal information and a careful consideration of differential diagnosis, and there is a potential for problems with both interrater and intergroup reliability. However, these same problems, including a differential diagnosis of the cause of symptoms, are also found in contemporary diagnostic criteria for schizophrenia, and for nearly all other psychiatric diagnoses as well.

Making this categorization in the context of controlled clinical trials is worth the relatively small amount of additional effort. The deficit syndrome is a disproportionate cause of impairment in schizophrenia (Fenton and McGlashan 1994; Kirkpatrick et al. 1996a,c) and the development of effective treatments for deficit features is an important goal. Moreover, recognition that the majority of patients with high scores on negative symptom ratings scales do not have the deficit syndrome should motivate clinicians to aggressively seek out and treat the causes of secondary negative symptoms. Recent developments in psychopharmacological and psychosocial treatments provide a growing arsenal of effective treatments for secondary negative symptoms.

Inaccurate claims of efficacy also undermine the development of effective treatment. If we have a false confidence in the efficacy of current treatments for the deficit syndrome, new avenues of research, such as the development of appropriate preclinical tests for the screening of candidate pharmaceuticals, may not be pursued. Clarity about the issues related to the treatment of the deficit syndrome will be necessary to make the desired progress in this area.

\section{ACKNOWLEDGMENTS}

Supported in part by PHS grants MH45074, MH40279, MH35996, MH48225, and MH56026, and grants from the National Alliance for Research on Schizophrenia and Depression.

\section{REFERENCES}

Amador XF, Kirkpatrick B, Buchanan RW, Carpenter WT, Marcinko L, Yale SA (1999): Stability of the diagnosis of deficit syndrome in schizophrenia. Am J Psychiatry 156:637-639

Andreasen NC (1982): Negative symptoms in schizophrenia. Definition and reliability. Arch Gen Psychiatry 39:784-788

Andreasen NC, Arndt S, Alliger R, Miller D, Flaum M (1995): Symptoms of schizophrenia. Methods, meanings, and mechanisms. Arch Gen Psychiatry 52:341-351

Andreasen NC, Olsen S (1982): Negative v. positive schizophrenia. Definition and validation. Arch Gen Psychiatry 39:789-794

Boyer P, Lecrubier Y, Puech AJ, Dewailly J, Aubin F (1995): Treatment of negative symptoms in schizophrenia with amisulpride. Br J Psychiatry 166:68-72

Breckler SJ, Steven J (1990): Applications of covariance struc- 
ture modeling in psychology: Cause for concern? Psychol Bull 107:260-273

Breier A, Buchanan RW, Kirkpatrick B, Davis OR, Irish D, Summerfelt A, Carpenter WT Jr (1994): Effects of clozapine on positive and negative symptoms in outpatients with schizophrenia. Am J Psychiatry 151:20-26

Buchanan RW, Brandes M, Breier A (1996): Pharmacological strategies for treating negative symptoms. In Breier A (ed), The New Pharmacotherapy of Schizophrenia. Washington, DC, American Psychiatric Press, pp 179-204

Buchanan RW, Carpenter WT (1994): Domains of psychopathology: An approach to the reduction of heterogeneity in schizophrenia. J Nerv Ment Dis 182:193-204

Buchanan RW, Kirkpatrick B, Heinrichs DW, Carpenter WT Jr (1990): Clinical correlates of the deficit syndrome of schizophrenia. Am J Psychiatry 147:290-294

Buchanan RW, Breier A, Kirkpatrick B, Elkashef A, Munson RC, Gellad F, Carpenter WT (1993): Structural abnormalities in deficit vs. non-deficit schizophrenia. Am J Psychiatry 150:59-65

Buchanan RW, Strauss ME, Kirkpatrick B, Holstein C, Breier A, Carpenter WT Jr. (1994): Neuropsychological impairments in deficit vs. nondeficit forms of schizophrenia. Arch Gen Psychiatry 51:804-811

Buchanan RW, Breier A, Kirkpatrick B, Ball P, Carpenter WT Jr (1998): Positive and negative symptom response to clozapine in schizophrenic patients with and without the deficit syndrome. Am J Psychiatry 155:751-760

Buchanan RW, Strauss ME, Breier A, Kirkpatrick B, Carpenter WT Jr (1997): Attentional impairments in deficit and nondeficit forms of schizophrenia. Am J Psychiatry 154:363-70

Bustillo JR, Thaker G, Buchanan RW, Moran M, Kirkpatrick B, Carpenter WT (1997): Visual information-processing impairments in deficit and nondeficit schizophrenia. Am J Psychiatry 154:647-654

Carpenter WT Jr, Lahti AC, Holcomb HH, Zhao M, Buchanan RW, Tamminga CA (1996): Frontal and parietal blood flow activation during an auditory task differentiate schizophrenic patients with and without primary negative symptoms. Abst Soc Neurosci 22:268.4

Carpenter WT Jr, Heinrichs DW, Alphs LD (1985): Treatment of negative symptoms. Schizophr Bull 11:440-452

Carpenter WT Jr, Heinrichs DW, Wagman AM (1988): Deficit and nondeficit forms of schizophrenia: The concept. Am J Psychiatry 145:578-583

Collaborative Working Group on Clinical Trial Evaluations (1998): Assessing the effects of atypical antipsychotics on negative symptoms. J Clin Psychiatry 59(Suppl 12):28-34

Crow TJ (1985): The two-syndrome concept: origins and current status. Schizophr Bull 11:471-486

Dollfus S, JM Ribeyre, M Petit (1996): Family history and deficit form in schizophrenia. Eur Psychiatry 11:260-267

Fenton WS, McGlashan TH (1992): Testing systems for assessment of negative symptoms in schizophrenia. Arch Gen Psychiatry 49:179-184

Fenton WS, McGlashan TH (1994): Antecedents, symptoms progression, and long-term outcome of the deficit syndrome in schizophrenia. Am J Psychiatry 151:351-356
Flaum M, Andreasen N (1995): The reliability of distinguishing primary versus secondary negative symptoms. Comprehen Psychiatry 36:421-427

Goff DC, Tsai G, Levitt J, Amico E, Manoach D, Schoenfeld DA, Hayden DL, McCarley R, Coyle JT (1999): A placebo-controlled trial of D-cycloserine added to conventional neuroleptics in patients with schizophrenia. Arch Gen Psychiatry 56(1):21-27

Goldberg SC (1985): Negative and deficit symptoms in schizophrenia do respond to neuroleptics. Schizophr Bull 11:453-456

Gur RE, Mozley PD, Shtasel DL, Cannon TD, Gallacher F, Turetsky B, Grossman R, Gur RC (1994): Clinical subtypes of schizophrenia: Differences in brain and CSF volume. Am J Psychiatry 151:343-350

Heresco-Levy U, Javitt DC, Ermilov M, Mordel C, Silipo G, Lichtenstein M (1999): Efficacy of high-dose glycine in the treatment of enduring negative symptoms of schizophrenia. Arch Gen Psychiatry 56:29-36

Kirkpatrick B, Amador XF, Flaum M, Yale SA, Gorman JM, Carpenter WT Jr, Tohen M, McGlashan T (1996a): The deficit syndrome in the DSM-IV Field Trial. I. Alcohol and other drug abuse. Depressive episodes and persecutory beliefs. Schizophr Res 20:67-78

Kirkpatrick B, Amador XF, Yale SA, Bustillo JR, Buchanan RW, Tohen M (1996b): The deficit syndrome in the DSM-IV Field Trial. Part II. Depressive episodes and persecutory beliefs. Schizophr Res 20:79-90

Kirkpatrick B, Buchanan RW (1990): Anhedonia and the deficit syndrome of schizophrenia. Psychiatry Res 31:25-30

Kirkpatrick B, Buchanan RW, Breier A, Carpenter WT Jr (1993): Case identification and stability of the deficit syndrome of schizophrenia. Psychiatry Res 47:47-56

Kirkpatrick B, Buchanan RW, Breier A, Carpenter WT Jr (1994): Depressive symptoms and the deficit syndrome of schizophrenia. J Nerv Ment Dis 182:452-455

Kirkpatrick B, Buchanan RW, McKenney PD, Alphs LD, Carpenter WT Jr (1989): The Schedule for the Deficit Syndrome: An instrument for research in schizophrenia. Psychiatry Res 30:119-124

Kirkpatrick B, Castle D, Murray RM, Carpenter WT (1999): Risk factors for the deficit syndrome of schizophrenia. Schizophr Bull, in press

Kirkpatrick B, Ram R, Amador XF, Buchanan RW, McGlashan T, Tohen M, Bromet E (1998): Summer birth and the deficit syndrome of schizophrenia. Am J Psychiatry 155:1221-1226

Kirkpatrick B, Ram R , Bromet E (1996c): The deficit syndrome in the Suffolk County Mental Health Project. Schizophr Res 22:119-126

Kopelowicz A, Liberman RP, Mintz J, Zarate R (1997): Comparison of efficacy of social skills training for deficit and nondeficit negative symptoms in schizophrenia. Am J Psychiatry 154:424-425

Kraepelin E (1971): Dementia Praecox and Paraphrenia [original work published in 1919]. New York, NY, Krieger

Loo H, Poirier-Littre MF, Theron M, Rein W, Fleurot O (1997): Amisulpride versus placebo in the medium-term treatment of the negative symptoms of schizophrenia. Br J Psychiatry 170:18-22 
Meltzer HY, Sommers AA, Luchins DJ (1986): The effect of neuroleptics and other psychotropic drugs on negative symptoms in schizophrenia. J Clin Psychopharmacol 6:329-338

Moller JH, Muller H, Borison RL, Schooler NR, Chouinard G (1996): A path-analytical approach to differentiate between direct and indirect drug effects on negative symptoms in schizophrenic patients. A re-evaluation of the North American risperidone study. Eur Arch Psychiatry Clin Neurosci 245:45-49

Nibuya M, Kanba S, Sekiya U, Suzuki E, Matsuo Y, Kinoshita N, Shintani F, Yagi G, Asai M (1995): Schizophrenic patients with deficit syndrome have higher plasma homovanillic acid concentrations and ventricular enlargement. Biol Psychiatry 38:50-56

Opler LA, Albert D, Ramirez PM (1994): Psychopharmacologic treatment of negative schizophrenic symptoms. Comprehen Psychiatry 35:16-28

Paillere-Martinot ML, Lecrubier Y, Martinot JL, Aubin F (1995): Improvement of some schizophrenic deficit symptoms with low doses of amisulpride. Am J Psychiatry 152:130-134

Ribeyre JM, Lesieur P, Varoquaux O, Dollfus S, Pays M, Petit M (1994): A comparison of plasma homovanillic acid in the deficit and nondeficit subtypes of schizophrenia. Biol Psychiatry 36:230-236

Rosenheck R, Dunn L, Peszke M, Cramer J, Xu W, Thomas J, Charney D (1999): Impact of clozapine on negative symptoms and on the deficit syndrome in refractory schizophrenia. Am J Psychiatry 156:88-93

Ross DE, Thaker GK, Buchanan RW, Lahti AC, Medoff D, Bartko JJ, Moran M, Hartley J (1996): Association of abnormal smooth pursuit eye movements with the deficit syndrome in schizophrenic patients. Am J Psychiatry 153:1158-1165

Strauss JS, Carpenter WT Jr, Bartko JJ (1974): The diagnosis and understanding of schizophrenia. Part III. Speculations on the processes that underlie schizophrenic symptoms and signs. Schizophr Bull 11:61-69

Tamminga CA, Thaker GK, Buchanan RW, Kirkpatrick B, Alphs LD, Carpenter WT, Chase TN (1992): Limbic system abnormalities identified in schizophrenia using PET/FDG and neocortical alterations with deficit syndrome. Arch Gen Psychiatry 49:522-530

Thibaut F, Ribeyre JM, Dourmap N, Menard JF, Dollfus S, Petit M (1998): Plasma 3-methoxy-4-hydroxyphenylglycol and homovanillic acid measurements in deficit and nondeficit forms of schizophrenia. Biol Psychiatry 43:24-30

Tollefson GD, Sanger TM (1997): Negative symptoms: A path analytic approach to a double-blind, placebo- and haloperidol-controlled clinical trial with olanzapine. Am J Psychiatry 154:466-474

Waltrip RW II, Buchanan RW, Carpenter WT Jr, Kirkpatrick B, Summerfelt A, Breier A, Rubin SA, Carbone KM (1997): Borna disease virus antibodies and the deficit syndrome of schizophrenia. Schizophr Res 23:253-258 